\author{
FEDERAL RESERVE BANK OF SAN FRANCISCO \\ WORKING PAPER SERIES
}

\title{
Modernization and discrete measures of democracy
}

\author{
Jess Benhabib, \\ New York University \\ Alejandro Corvalan, \\ Universidad Diego Portales \\ Mark M. Spiegel, \\ Federal Reserve Bank of San Francisco
}

January 2014

Working Paper 2014-01

http://www.frbsf.org/economic-research/publications/working-papers/wp2014-01.pdf

The views in this paper are solely the responsibility of the authors and should not be interpreted as reflecting the views of the Federal Reserve Bank of San Francisco or the Board of Governors of the Federal Reserve System. 


\title{
Modernization and discrete measures of democracy
}

\author{
Jess Benhabiba, \\ Alejandro Corvalan ${ }^{b}$, \\ and \\ Mark M. Spiegel ${ }^{c}$
}

January 14, 2014

\begin{abstract}
We reassess the empirical evidence for a positive relationship between income and democracy, commonly known as the "modernization hypothesis," using discrete democracy measures. While discrete measures have been advocated in the literature, they pose estimation problems under fixed effects due to incidental parameter issues. We use two methods to address these issues, the biascorrection method of Fernandez-Val, which directly computes the marginal effects, and the parameterized Wooldridge method. Estimation under the Fernandez-Val method consistently indicates a statistically and economically important role for income in democracy, while under the Wooldridge method we obtain much smaller and not always statistically significant coefficients. A likelihood ratio test rejects the pooled full sample used under the Wooldridge estimation method against the smaller fixed effects sample that only admits observations with changing democracy measures. Our analysis therefore favors a positive role for income in promoting democracy, but does not preclude a role for institutions in determining democratic status as the omitted countries under Fernandez Val-fixed effect method appear to differ systematically by institutional quality measures which have a positive impact on democratization.

JEL Classification Nos.: P16, 010, O11

Keywords: Income, Democracy, Modernization Theory, Sample selection, Dynamic panel

a New York University, 19 W. 4th Street, 6FL, New York, NY, 10012, United States, b Universidad Diego Portales, Santiago de Chile, Chile, c Federal Reserve Bank of San Francisco, 101 Market St., San Francisco, CA, 94105, United States. Helpful comments were received from Chris Flynn, Bill Green and Oscar Jorda. Eric Hsu and Israel Malkin provided excellent research assistance. The views expressed here are our own and in no way represent those of the Federal Reserve Bank of San Francisco or the Board of Governors of the Federal Reserve System.
\end{abstract}




\section{Introduction}

Recently some doubts have emerged concerning the validity of the Lipset (1959) hypothesis of a positive relationship between democracy and economic development. In recent papers, Londregan and Poole (1996) and Acemoglu, et al (2008) demonstrate that the relationship between income and democracy observed in the raw data is not robust to the inclusion of country fixed effects which may proxy for, among other things, national institutional quality. Others have recovered the positive relationship in the data through adjustments for econometric issues [e.g. Bobba and Coviello (2007), Boix (2011), and Benhabib, et al (2013)], by separating the sample by income categories [Moral-Benito and Bartolucci (2012)], initial democratic status [Papaioannu and Siourounis (2008), or using a longer time series [Murtin and Wacziarg (2013)].

While the literature has primarily concentrated on polychotomous measures of the extent of democracy, such as the Freedom House and Polity measures used by Acemoglu, et al (2008), or the Gurr, et al (1990) measures used by Londregan and Poole, a similar controversy also exists among studies based on the discrete democracy measures proposed by Alvarez, et al (1996) and Cheibub, et al (2010). Przeworski and Limongi (1997) advocate the use of dichotomous measures of democracy on the basis of whether offices are appropriately contested. ${ }^{1}$

The use of the dichotomous measures of democracy however raises econometric issues. First, because the number of parameters grows at the same rate as the number of cross-section observations, consistency is not guaranteed as unobserved time-invariant characteristics are replaced by estimates. This issue is commonly referred to as the "incidental parameters problem," first noted by Neyman and Scott (1948). Second, because changes in democratic status are infrequent, the introduction of country fixed effects has a marked impact on our sample. Countries that have not experienced a transition

\footnotetext{
${ }^{1}$ In practice, the dichotomous measures of democracy that proposed by Przeworski and Limongi (1997) are strongly correlated with the other polychotomous measures in the literature.
} 
between democratic and autocratic status need to be dropped from the sample when conditioning for time-invariant country characteristics. As such, we face a choice between two alternatives: Conditioning for fixed effects, but dropping those countries whose democratic status is unchanging over the course of our sample, or proxying for fixed effects with indicators based on country characteristics and initial values.

Acemoglu, et al [AJRY (2009)] use the dichotomous democracy measures of Alvarez, et al (1996) and conduct similar investigations to their earlier study, obtaining roughly the same results. They confirm that a statistically significant positive relationship between income and democracy holds under OLS for dichotomous measures of democracy without the inclusion of country fixed effects, but the role for income diminishes markedly and becomes insignificant when country fixed effects are included in the specification. ${ }^{2}$ They also deal with the incidental parameters problem under fixed effects estimation by using the Chamberlin (1980) approach of conditioning on average values of lagged income and using a random effects estimator to obtain similar results. They acknowledge that their random effects specification " ... is less flexible than including a full set of fixed effects ... because it imposes considerable structure on how unobserved heterogeneity (omitted time-invariant factors) affects democratic transitions" [AJRY (2009), pg. 1053]. However, they conclude that regardless of whether they control for fixed effects directly, as they do by differencing under OLS or by using the Chamberlin (1980) approach, introducing these controls removes the relationship between income per capita and democracy.

Ideally one would like to assess the modernization question with full fixed effects in a properly specified nonlinear model that also addresses the incidental parameters problem. In this paper, we use the "Large-T" bias correction of Fernandez-Val (2009) to correct the bias due to incidental parameters

\footnotetext{
${ }^{2}$ As AJRY (2009) point out, their use of differencing in their OLS specifications avoids the aforementioned incidental parameters problem, although a nonlinear specification, such as the unconditional LOGIT, is clearly the appropriate specification for a discrete democracy variable.
} 
issues in a logit specification with fixed effects. Our results suggest an influential role for income under the Fernandez-Val methodology. For example, growth spurts in which a country's income doubles in a period of 20 years or less are not uncommon in our data. Such growth spurts occur in $27 \%$ of the countries in our full Wooldridge sample, and $50 \%$ of the time in our sample of changing countries used under Fernandez-Val estimation. For such a doubling of income, our point estimates indicate that a country experiences a 22 percentage point increase in the probability of being a democracy using the Penn sample, and a 31 percentage point increase using the Maddison sample.

The Fernandez-Val estimator has the advantage of providing actual rather than parametric conditioning for country differences in a nonlinear specification, but it does not admit those countries whose democratic status fails to change over the course of our sample period. Focusing only on withincountry variations in the data and omitting countries where the dependent variable is constant throughout the sample is of course the right approach when using fixed effects. Still, it appears that the use of formal fixed effects has the undesirable property of discarding some information in the data. Large income changes within a country with an unchanging democracy status could likely be "informative" if the constancy of democratic status is explained by the time-invariant country factor.

We therefore augment our Fernandez-Val analysis with a parameterized fixed effect specification using the methodology of Wooldridge (2005), which extends the estimator proposed by Chamberlin (1980) to the case of dynamic panels. This parameterized method replaces the fixed effect variables representing the time-invariant country components, and admits the full sample for estimation. The two methods yield conflicting results: estimation under Fernandez-Val consistently indicates a statistically and economically important role for income in democracy, while we obtain much smaller and not always statistically significant coefficient estimates under Wooldridge. 
Our results indicate that these discrepancies are only partly due to differences in estimation methods, and instead are primarily attributable to the substantively reduced sample admissible under fixed effects estimation. In particular, we find that limiting our unbalanced sample to countries with changing democratic status and using the Wooldridge estimation method produces a statistically significant role for income and a diminished, but still economically important role as well. Our point estimates then indicate that a doubling of income would result in a 10 percentage point increase in the probability of being a democracy using the Penn sample, and a 12 percentage point increase using the Maddison sample. As such, the empirical relationship between income and discrete measures of democracy appears to hang on whether or not countries with unchanging democratic status are included in the sample. While the Fernandez-Val method directly includes fixed effects and assigns a significant role to lagged income to explain democratic status, it does so using a method that cannot capture the information coming from countries with unchanging democratic status, quite plausibly due to country specific institutional factors.

It is not clear a priori however that it is appropriate, in using the Wooldridge methodology, to pool countries with unchanging democratic status with those that experience changes over the course of our sample. To check this we run a likelihood ratio test on the validity of pooling the changing and unchanging countries under Wooldridge estimation. This is a joint test, taking the stability of all of the coefficients in our specification as our null hypothesis. Using PWT 7.1 income data, we obtain a chisquare statistic for the likelihood ratio test of 71.46. Using the Maddison data we obtain a chi-square statistic of 56.39. Both reject the validity of pooling under Wooldridge with a p-value of less than $1 \%$, casting some doubt on our full sample results.

While our results for the reduced sample indicate a role for income in the determination of democratic status, they do not necessarily refute the hypothesis that institutional quality is an important 
determinant of democratic status. As we demonstrate below, countries that are excluded from our estimation because they are autocratic or democratic throughout our sample are markedly different in characteristics that can be associated with institutional quality. Countries that remain autocracies throughout our sample appear to have inferior institutional quality relative to included countries, while those that are excluded because they remain democracies throughout appear to have superior institutions. It appears therefore that overall institutional quality plays an important role in driving the sample selection in our study.

An alternative way to increase the share of countries with changing democratic status is to increase the length of the time series in our panel. We therefore pursue this method as a robustness check by evaluating a panel of countries with time series going all the way back to 1900 . This reduces the number of countries in our balanced cross-section to 20 countries. ${ }^{3}$ Moreover, this sub-sample is likely over-represented with wealthier countries with superior institutions that kept records over this longer period. For this reason we present these results as a robustness check of our full-sample results for the shorter time period.

Our results for this longer sample indicate that income plays a positive and statistically significant role in democratization. Our point estimates under Fernandez-Val estimation indicate that doubling income would correspond to a 15 percentage point increase in the probability of being a democracy. As in the shorter sample, the coefficient estimate decreases when the full sample including countries with unchanging democratic statuses is used under Wooldridge estimation, but the coefficient estimates even for this pooled sample are higher than those found for our shorter sample and indicate a non-trivial positive role for income. Moreover, likelihood ratio tests again reject pooling in favor of the smaller sample of changing countries where income plays a prominent role in democratization.

\footnotetext{
${ }^{3}$ Our unbalanced panel still has 156 overall.
} 
Finally, Acemoglu et al (2009) also consider the impact of observable indicators of historical institutions on democracy. ${ }^{4}$ As a further robustness check, we repeat their exercise using their data. Our results are qualitatively similar to those we obtain using our Wooldridge or Fernandez-Val methodologies. We confirm a positive and statistically significant role for income for our reduced sample of countries with changing democracies. With our full sample including unchanging countries, however, income no longer enters significantly at standard confidence levels. Nevertheless, likelihood ratio and Wald test results also reject the validity of the pooling assumption implicit in the full sample under these specifications, rendering these estimates suspect and advocating for those obtained using the reduced sample.

Interestingly, however, our results with the reduced sample also indicate a positive role for institutional quality, at least as measured in the form of constraints on the executive. That indicator consistently enters positively and significantly, suggesting a role for institutional quality as well as income in democratization. As such, our overall results favor a synthesis between these two hypotheses.

\section{Data and methodology}

\subsection{Data}

We use two alternative measures of income. We use income data from the Penn World Tables (7.1)[Heston et al (2012)], heretofore referred to as PWT 7.1. We also use the Maddison Statistics on World Population, GDP and Per Capita GDP countries [Maddison (2003)]. Our Maddison data set tends to have greater coverage per country, facilitating the estimation of within-country variations. Our base sample for logit using PWT 7.1 includes data for 182 countries from 1960 to 2000, while that using the

\footnotetext{
${ }^{4}$ See Acemoglu, et al (2009), Table 6, panel C (pg. 1056) for results using discrete democracy measures.
} 
Maddison data includes data for 160 countries from 1960 to2000.As some countries received independence during this period, our base sample is unbalanced. We aggregate the data into five-year intervals to eliminate business cycle effects. We follow AJRY (2009) in estimating our unbalanced panels using our complete 1960-2000 series, while limiting our balanced panel estimation to the 1965-2000 series. ${ }^{5}$

We next turn to the measurement of democracy. Much disagreement exists about the proper way to measure this variable (see Elkins (2000), Munk and Verkuilen (2002), Coppedge, et al (2008), and Cheibub, et al (2010) for recent discussions). In this paper, we follow Przeworski and Limongi (1997) and concentrate on a dichotomous measure of democracy. Cheibub et al (2010) advocate the use of dichotomous measures of democracy, claiming that while differences in levels of democracy exist, countries are truly either democracies or not on the basis of whether offices are contested. In particular, these authors argue that including more dimensions along which to classify political regimes leaves it difficult to identify causal mechanisms between country characteristics and democracy. There are 20 dimensions of characteristics in Freedom House democracy measures, while Polity measures, the other commonly-used polychotomous measure, aggregates a single score over hundreds of possible response patterns, leaving interpretation of the meaning of the scalar score difficult.

We use the Democracy-Dictatorship (DD) measure introduced by Alvarez et al (1996) and extended by Cheibub et al (2010). This index gives a country a value of 1 at time $t$ if it is considered a democracy and 0 otherwise. A regime is classified as a democracy if the following four conditions are all met: (1) the chief executive is chosen in a popular election, or by a popularly-elected legislature, (2) the legislature is popularly elected, (3) there is more than one political party competing in elections, and (4)

\footnotetext{
${ }^{5}$ This is done to increase sample size. As our specification calls for lagged values, including 1960 observations requires data for 1955, which dramatically reduces the size of our balanced panel samples from 296 observations to 216 observations and from 37 to 24 countries.
} 
an alternation in power under electoral rules identical to the ones that led to the incumbent taking power must have taken place.

\subsection{Estimation methodology}

Given our binary measure of democracy, a nonlinear specification for the relationship between income and democracy is appropriate. We consider the following logit specification:

$$
\operatorname{Pr}\left[d_{i t}=1 \mid d_{i t-1}, \log y_{i t-1}, \delta_{t}, c_{i}\right]=F\left(\alpha d_{i t-1}+\beta \log y_{i t-1}+\delta_{t}+c_{i}\right)
$$

where $d_{i t}$ and $\log y_{i t}$ represent the state of democracy and income in country $i$ at time $t$ respectively, while $c_{i}$ represents a country $i$ fixed effect, while $\delta_{t}$ represents a time dummy and $\mathrm{F}(\bullet)$ is the cdf of a logistic function.

Our dynamic panel includes lagged values of democracy. Given our nonlinear specification, we cannot use differencing to eliminate the impact of country fixed effects. Taking the initial condition of the dependent variable as independent of unobserved heterogeneity will bias estimates in dynamic panels that are short in the time dimension. A number of authors have addressed this problem with various methods, including Heckman and MacCurdy (1980), Heckman (1981), Honoré (1993), Honoré and Kyriazidou (2000), and Wooldridge (2005).

In this paper, we use the Fernandez-Val (2009) correction for the incidental parameter bias. Incidental parameter bias can arise because unobserved individual characteristics are replaced by sample estimates, which will contain errors, potentially biasing estimates of model parameters. Fernandez-Val provides a correction for this potential bias that does not impose parametric assumptions on individual heterogeneity. We also follow Wooldridge (2005) in assuming that country fixed effects 
can be specified as a linear function of the mean sample value of the observable independent variables, the initial condition for the lagged dependent variables and country specific random effects. ${ }^{6}$ This approach is a generalization of the Chamberlain (1980) methodology used by AJRY (2009). ${ }^{7}$

A difficulty associated with estimation under the Wooldridge method stems from the parameterization methodology. Under Wooldridge, we use initial democratic status and mean income to proxy for our omitted country fixed effects. Unsurprisingly, mean income is highly correlated with our variable of interest, last period's income. For our full sample, the correlation coefficient between mean income and last period's income is $0.97 .^{8}$ As such, it is likely that the explanatory role for income in the data will be apportioned in part to the proxy for the parameterization of the omitted fixed effects.

A priori, one might consider the Fernandez-Val (2009) estimation method preferable to the Wooldridge (2005) method because it does not impose the aforementioned parametric assumptions. However, its implementation requires both the use of a balanced panel and a panel limited to countries with variations of democratic status in the time dimension. As we demonstrate below, the omission of countries that do not change their democratic status has a non-trivial impact on both our sample and our results.

\section{Base Results}

Our base specification results are shown in Table 1. Results for logit specification average partial effects without country fixed effects are shown in Models 1 and 2. As in the previous literature [e.g.

\footnotetext{
${ }^{6}$ Rabe-Hesketh and Skrondal (2013) propose to add the initial value of the dependent variable to this approximation. Our results are robust to their specification.

7 The estimation method is also sometimes referred to as "correlated random effects".

${ }^{8}$ The correlation between mean income and lagged income is high because incomes are serially correlated within countries and they differ significantly across countries. For example in a country where income is constant, the correlation between mean income and lagged income is 1.
} 
Acemoglu, et al (2009)], we confirm a statistically significant positive relationship between lagged income and democracy, but one that does not appear to be economically important. Our point estimates indicate that a one standard deviation increase in income is associated on average with only a 5.0 percentage point increase in the probability of being a democracy using the PWT 7.1 sample, and a 6.4 percentage point increase using the Maddison sample. ${ }^{9}$

However, these results do not allow for the consideration of country fixed effects. We introduce these into our logit specifications in Models 3 and 4. It can be seen that our sample is markedly reduced with the introduction of country fixed effects, from 1,114 observations to 431 observations using the PWT 7.1 income data. This reflects the fact that most of the countries in our sample do not change their democratic status over the course of our sample, either remaining autocracies or democracies throughout.

For the sub-sample that can be estimated, we obtain a substantial role for income in the determination of democratic status. With country fixed effects included, our point estimates indicate that a one standard deviation increase in income is predicted to increase the probability of democracy by 33 percentage points for the PWT 7.1 sample, and by 34 percentage points under the Maddison sample. However, these coefficient estimates are subject to the incidental parameters bias discussed above.

To correct for this problem, we consider two alternative estimation techniques. The FernandezVal (2009) method using fixed effects with balanced panels directly corrects the incidental parameter bias. The Wooldridge (2005) method parameterizes the fixed effects using initial democratic status and mean income of each country, thereby avoiding the bias.

\footnotetext{
${ }^{9}$ Standard deviations of log income for the samples considered in this paper are shown in appendix Table A1.
} 
We report the results using the Fernandez-Val method with PWT 7.1 and Maddison income data in Models 5 and 6 respectively. This further reduces the sample, because the Fernandez-Val method requires the use of a balanced panel, leaving us with 216 observations using the PWT 7.1 data. It can be seen that we not only continue to obtain a statistically significant positive coefficient estimate on income, but the estimated values of the average partial effect of income remain quite large. Our point estimates under the Fernandez-Val specification indicate that a one standard deviation increase in income is associated on average with a 22 percentage point increase in the probability of being a democracy using the PWT 7.1 sample, and a 32 percentage point increase in the probability of being a democracy using the Maddison sample.

We also address the incidental parameters problem under Wooldridge estimation. Rather than explicitly using fixed effects, we proxy for initial conditions through mean income and initial democracy. This allows for our estimation of the full sample, including countries with unchanging democratic statuses. The results are shown in Models 7 and 8 . It can be seen that income continues to enter significantly positive as a determinant of democracy. However, the magnitudes of our average partial effect estimates are substantially reduced. Our point estimates under the Wooldridge specification indicate that a one standard deviation increase in income is associated on average with only a 10 percentage point increase in the probability of being a democracy using the PWT 7.1 sample, and a 6.4 percentage point increase in the probability of being a democracy using the Maddison sample.

While both methods indicate a positive role for income, the results are clearly much weaker under Wooldridge estimation. One reason may be in the parameterization used for country fixed effects. However the sample size using Fernandez-Val estimation is also much smaller than the sample under Wooldridge estimation. A priori, it is unclear what effect the sample reduction would have on our results. The substantial estimated role of income under the Fernandez-Val estimation method, 
combined with the substantive reduction in our sample under that method, suggests that the sample differences may be responsible for the discrepancies in our estimates under the two methods. We move towards evaluating the relative importance of these components of the sample differences in the following section.

\section{Impact of sample differences}

\subsection{Characteristics of reduced and full samples}

In this section, we investigate the role that sample differences play in our Wooldridge and Fernandez-Val estimation results. Table 2a shows the geographic breakdown of the full sample, as well as the share of countries in the full sample that experienced a change in democratic status. ${ }^{10}$ It can be seen that some regions -- most notably the Indian and Chinese sub-continents, Latin America, Africa, and Eastern European regions -- have a greater share of countries that experienced some change in their democratic status over the course of our sample. Because these countries demonstrate exceptional variability in their democratic status relative to our full sample, they end up being disproportionately represented in our reduced sample.

Conversely, the countries from Western Europe, North America, and the Middle East have a notably smaller share of changes in their democratic status. ${ }^{11}$ However, this group of "unchanging countries" is quite heterogeneous, as it includes unchanging autocracies and democracies. The Western European and North American countries tend to remain democracies throughout our sample, while many of the Middle Eastern countries remain autocracies throughout. It is therefore difficult to make

\footnotetext{
${ }^{10}$ Table $2 a$ is the full unbalanced panel sample from 1960 of 1,114 observations.

${ }^{11}$ Mexico is included in the North America region rather than the Latin America region.
} 
generalizations about the differences in the characteristics of countries admitted into our Fernandez-Val estimation and those that are omitted due to their unchanging democratic statuses. The Western European and North American countries that are disproportionately omitted when we move to the reduced Fernandez-Val sample tend to be wealthier countries with stronger institutions relative to the full sample, while the autocratic Middle Eastern countries that are excluded are just the opposite. Overall, it is difficult to say a priori how the exclusion of unchanging countries will affect our results.

Nonetheless, the characteristics of countries that are omitted from our reduced sample appear to differ systematically from those that are included, as shown in Table $2 \mathrm{~b}$. Countries that experienced a change in democracy tend to have lower income on average than those that did not using both the PWT 7.1 and the Maddison income data. Countries experiencing some change in their democratic status over the course of our sample tend to be closer to the equator, have higher rates of settler mortality, and lower Economic Freedom of the World (EFW) overall scores, all of which would be associated with inferior institutional quality. However, they also have lower population densities in 1500, and modestly earlier independence years, which would tend to be associated with higher institutional quality, holding all else equal. Overall, it appears that the unchanging democracy countries have somewhat superior institutions relative to our changing reduced sample.

However, these modest differences become much larger when we separate the set of unchanging countries into unchanging democracies and autocracies ( $D=1$ and $D=0$ respectively). The final two columns of our sample split the set of unchanging countries into those that remain democracies and those that remain autocracies throughout. Here, we observe a dramatic difference. Countries that remain autocracies throughout the course of our sample are far poorer and have substantially worse institutions than those that exhibit a change in their democratic status. In contrast, those that remain democracies throughout are much wealthier and have superior institutions relative to 
the set of countries exhibiting a change in their democratic status. It would therefore be more accurate to say that we have three sets of countries in our full sample: Those that remain democracies throughout, those that remain autocracies throughout, and those that exhibit a change in their democratic status. Our Fernandez-Val sample excludes the first two of these. The exclusion of the countries that remain autocracies even as their income rises throughout should push the estimated coefficient on income up, and similarly, the exclusion of the wealthy set of nations that remain democracies as their income rises or fluctuates throughout our sample should push the estimated coefficient on income down.

\subsection{Results for reduced sample}

To gauge the implications of the sample reduction, we re-estimate the specification using the Wooldridge method with the sample reduced to that we used under fixed effects logit. These results are shown in Models 1 and 2 of Table 3. It can be seen that the reduction of the sample increases the coefficient estimates on income substantively relative to the full sample Wooldridge results in Table 1. Our point estimates increase from 0.04 ( 0.06 for Maddison) with the full sample to 0.15 ( 0.17 for Maddison) under the reduced sample. These values indicate that a one standard deviation increase in income is associated on average with a 14.7 percentage point increase in the probability of being a democracy using the PWT 7.1 sample, and a 14.4 percentage point increase in the probability of being a democracy using the Maddison sample.

Our results where we estimate the full sample, but allow the coefficient estimate to differ between the observations from countries where we have no change in democratic status over the course of our sample and those where we do (Models 3 and 4), are similar. We obtain a large positive and significant coefficient estimate on income for the observations from countries that exhibited some 
change over the course of our sample, 0.17 and 0.15 for the PWT 7.1 and Maddison data sets respectively. In contrast, we obtain modestly negative point estimates for income for the sub-sample of observations from countries where there is no change in democratic status, with the coefficient estimate being significantly negative for the PWT 7.1 sample.

Our results indicate that a substantial portion of the differences we observed initially in our coefficient point estimates using the Wooldridge and Fernandez-Val estimation methods were attributable to the differences in the samples available for estimation under these two methods. Observations are necessarily omitted from the Fernandez-Val sample because of the need for a balanced panel and the inadmissibility of countries that exhibit no change in their democratic status. The additional reduction in the estimated role for income under Wooldridge relative to Fernandez-Val appears attributable to the difference in the estimation methods.

Given the differences we observe, the pooling assumptions implicit in the full-sample Wooldridge specifications (Table 1, Models 7 and 8 ) may be problematic. To test if this is the case, we calculate the likelihood that the coefficient estimate on income changes with the addition of the countries with unchanging democratic status. To do this, we take the full and reduced sample estimations under Wooldridge and test whether the income estimated coefficients are the same for the two samples. Our test yields a likelihood ratio test value of 71.46 for the PWT 7.1 sample, and 56.39 for the Maddison data. Both reject the validity of pooling at a $1 \%$ confidence level. As such, we reject the results we obtain under Wooldridge using the full sample, and are left with our reduced sample Wooldridge results which indicate a positive role for income in democratization under Wooldridge estimation. $^{12}$

\footnotetext{
${ }^{12}$ We also explored splitting the sample by lagged democratic status to check whether the coefficient on lagged income differs depending on whether countries are autocracies or democracies in the previous period. We did not find that the lagged income coefficients differed according to prior democratic status.
} 


\section{Marginal effects at different income levels}

Our results demonstrate that the estimate one gets for the impact of income changes on democracy is sensitive to the estimation method used, in part because the estimation method has sample implications. Nevertheless the marginal effects of income may still differ by the level of income, irrespective of the estimation method. Indeed, previous studies, such as Moral-Benito and Bartolucci (2012), have found that income has a positive effect on levels of democracy using Freedom House or Polity measures for low-income countries, but has no significant effect among high-income countries. Przeworski and Limongi (1997) have also argued that affluent democratic nations tend to remain democratic. This contention seems correct in our sample, as the countries remaining democratic throughout our sample are substantially more affluent than the rest.

The marginal effects of income for different income levels using the PWT 7.1 income measures are displayed in Figure 1 with 95\% confidence intervals. We display the results from logit estimation, Wooldridge estimation with the reduced sample, and Wooldridge estimation with the full sample. This allows for comparison as the first two histograms reflect estimation under the same samples, but different estimation methods, while the latter two represent similar estimation methods, but different samples.

Some similarities are apparent. All of the marginal patterns are hump-shaped, with interior income values indicating the highest impacts, although the full-sample Wooldridge results only decline modestly at the highest sample values. This is consistent with high income and democratic countries being unlikely to become autocratic with a modest perturbation in their incomes, and for low-income autocratic countries being unlikely to become democracies with small income perturbations. In contrast, we observe relative strong marginal effects for income for intermediate income levels. 
For example, our marginal effects under logit estimation peak at log income of 7.9. At that income level, we observe a marginal effect equal to 0.33 . Such an effect would correspond to a one standard deviation increase in income resulting in a 41.6 percentage point increase in the probability of a country being a democracy under the PWT sample, and a 35 percentage point increase under the Maddison sample. Moreover, the $95 \%$ confidence interval indicates that at a minimum, the marginal effect at that income levels is equal to 0.22 , implying that a one standard deviation increase in income would correspond to a 27.7 percentage point increase in the probability of a country being a democracy under the PWT 7.1 sample, and a 23.5 percentage point increase under Maddison.

The results are weaker under reduced-sample Wooldridge estimation, but there are still income values with substantive and statistically significant marginal effects. Under the reduced sample our marginal effects peak at log income of 8.73. At that income level, we observe a marginal effect equal to 0.17. Such an effect would correspond to a one standard deviation increase in income resulting in a 16.7 percentage point increase in the probability of a country being a democracy under the PWT 7.1 sample, and a 14.5 percentage point increase under the Maddison sample.

Under the full sample using the Wooldridge estimation, we obtain lower marginal effect estimates, but there remain income values with point estimates indicating a substantive positive and statistically significant role for income in the determination of the probability of democracy. Our marginal effect point estimates peak at 0.15 , at a higher income level of 9.56 . This value would indicate that a one standard deviation increase in income would result in a 19.0 percentage point increase in the probability of a country being a democracy under PWT 7.1 and a 16.1 percentage point increase under the Maddison sample.

It may be that the differences in marginal effects by income simply reflect the pattern identified above that there is more variability in the data for intermediate income values than at very rich and 
poor levels, many of which appear to remain as democracies and autocracies throughout our sample respectively. This is confirmed in Figure 2, which plots the point estimates from a Probit looking at the relationship between the log of income of a country in 1970, as well as the square of that term, and the occurrence of any change in democratic status over the course of our sample as a function of initial income. It is clear that countries with intermediate levels of income are more likely to exhibit some change in their democratic status, implying that those countries are the ones where we might expect to obtain the most information about the role of income in the probability of democracy. ${ }^{13}$ Fitted values for the probability of a regime change over the course of our sample range from 0.1 for the lowest democracy levels to intermediate values over 0.4 , and then fall arbitrarily close to zero for the highest income levels.

\section{Robustness checks}

\subsection{Sample reduction by geographic regions}

The omission of countries when moving from the full to reduced samples is systematically related to regions of origin. In particular, we found that in the reduced sample countries from Eastern Europe and Latin America are over-represented, as countries in these regions exhibit higher shares of changes in democratic status than our overall sample. We also found that countries from the Middle East and Western Europe are under-represented, as these countries exhibit lower shares of changes in democratic status than our overall sample. In this section we investigate whether these regions are exceptional by dropping them from our full sample Wooldridge specification.

\footnotetext{
${ }^{13}$ Probit estimation is available upon request. Initial income obtains a coefficient estimate of 4.36 with a robust standard error estimate of 1.62 , while initial income squared obtains a coefficient estimate of -0.28 with a robust standard error estimate of 0.10 . Both are therefore statistically significant at a $1 \%$ confidence level.
} 
Our results are shown in Table 4. We eliminate countries from specific regions one at a time from our changing sample Wooldridge estimation. It can be seen that income always enters positively and retains its statistical significance at least a $10 \%$ confidence level in 6 of the 8 specifications. The exceptions are Model 3, where Western European countries are excluded, and Model 5, where Latin American countries are excluded. Even these sub-samples, however, indicate a notable role for income in the determination of democracy, as both coefficient point estimates are 0.12 which implies that a one standard deviation of income would correspond to a 12 percentage point increase in the probability of a country being a democracy for both models. The point estimates for the remaining six specifications where income enters significantly range from 0.14 to 0.18 .

\subsection{Expanded time series}

An alternative way to mitigate the selection issues discussed above would be to increase the share of the sample with countries that change their democratic statuses by increasing the span of the sample time series (see, for instance, Murtin and Wacziarg, 2013). We do that by using data going back to 1900 , which with our lagged term allows for a sample that goes from 1905 to 2000 . This increases the share of changing countries in our unbalanced sample to almost half, as 74 of the 156 countries in this longer time series sample exhibit at least one change in democratic status. However, as the Cheibub (2010) democracy-dictatorship data does not go back this far, we instead use a discretized version of the Polity IV sample as our indicator of democracy, where countries with a positive or zero score under Polity IV are considered democracies, and those with strictly negative scores are considered autocracies.

Our results are shown in Table 5 using the Maddison data. We first report unconditional logit results with country and year fixed effects. With this longer series, our unbalanced panel sample now includes 74 countries and 866 observations. As was the case for the shorter sample using the Cheibub 
democracy indicator, we obtain a substantive positive and statistically significant coefficient estimate on income of 0.18 (Model 1). This point estimate indicates that a one standard deviation increase in income would correspond to a 15.3 percentage point increase in the probability that a country is a democracy. Moving to a balanced panel (Model 2), our sample is substantively reduced, to 238 observations and 14 countries. ${ }^{14}$ Our unconditional logit results still indicate a substantive coefficient on income of 0.13 , which remains statistically significant.

Of course, these results are also subject to the incidental parameters problem, so we again correct for this issue using both the Fernnadez-Val and Wooldridge methods. The Fernandez-Val method requires the use of the balanced sample. The results, shown in Model 3, again indicate a substantive and statistically significant positive role for income, with a point estimate of 0.22 , although the coefficient is only significant at a $10 \%$ confidence level.

As above, proxying for country characteristics using the Wooldridge estimation method admits the use of our entire sample. Our unbalanced sample includes 156 countries with 1,482 observations. Our results with this sample (Model 4) are similar to those for the full sample in our base sample. We obtain a statistically significant positive coefficient for income, but its magnitude is decreased to 0.09 . Such a value indicates that there is a notable role for income in democratization, the point estimate indicates that a one-standard deviation increase in income would correspond to a 8.8 percentage point increase in the probability of being a democracy. However, this reduced point estimate leaves open the possibility that other country characteristics, including institutional quality, may also be influencing democratization. As above, we obtain marked increases in our income coefficients by reducing the

\footnotetext{
${ }^{14}$ Notice that these figures imply 17 observations for each country, the reason being that democracy is not changing in those countries after 1985.
} 
sample to countries with changing democratic statuses. For the unbalanced panel of 74 democracychanging countries, the coefficient under Wooldridge estimation increases to $0.13 .{ }^{15}$

As above, we used a Wald test on our Wooldridge to examine the relative validity of estimates we obtain under the full and changing-only samples. Our test rejects the validity of pooling at a greater than $1 \%$ confidence level. ${ }^{16}$ As such, we concentrate on our Fernandez-Val, logit, and Wooldridge results with the reduced changing sample. All of these indicate substantive and statistically significant positive roles for income in democratization.

\subsection{Proxies for institutional quality}

Acemoglu, et al (2009) also consider three widely-available time-invariant proxies for institutional quality: the year of independence, the severity of constraints placed on the chief executive at independence, and the density of population in the year 1500. We repeat their exercise using their data in Table 6, examining both specifications with all three institutional indicators as well as with the population density variable omitted.

Models 1 and 2 report our results following Acemoglu, et al (2009) in using ordinary least squares estimation with our full sample and two and all three institutional variables respectively. As in their paper, income enters with a very small coefficient estimate (0.04 in both cases). Two of the three institutional variables, the year of independence and constraints on the chief executive, enter significantly with their predicted signs whether or not the population density variable, which is

\footnotetext{
${ }^{15}$ We also estimated the balanced changing sample we used under Fernandez-Val using the Wooldridge method. Our results were similar, with income obtaining a 0.154 coefficient point estimate that was statistically significant at a $5 \%$ confidence level.

${ }^{16}$ We obtain a likelihood ratio test value of 36.61 , which rejects the null at a greater than $1 \%$ confidence level.
} 
insignificant itself, is included. Our results for the full sample under logit estimation (Models 3 and 4) yield even smaller income coefficient estimates.

Given our results above, however, we remain skeptical about the validity of pooling the changing and unchanging democratic status countries in our sample. We therefore again ran a series of likelihood ratio tests for the validity of the implicit pooling in our full sample. As before, we reject parameter stability in the changing and unchanging samples at more than a $1 \%$ confidence level. ${ }^{17}$

We therefore repeat our tests for the subset of countries with changing democratic statuses. This reduced sample includes 29 countries for a total of 219 observations. Our results are shown in Models 4 through 8. Using either OLS or logit estimation, we consistently obtain a positive and significant income coefficient estimate, with point estimates ranging from 0.20 to 0.22 . Among the institutional variables, the "constraints on the executive" institutional quality proxy consistently enters at statistically significant levels with its expected positive sign. The other two institutional variables are insignificant. Overall, our results using the Acemoglu, et al (2009) data support a role for both institutional quality, as proxied by constraints on the executive at independence, and income.

\section{Conclusion}

This paper reassesses the empirical relationship between income levels and democracy. On the whole our results indicate a substantive role for income in the determination of discrete democratic status, especially for intermediate income countries. However, ourresults also appear to favor a synthesis where both income and institutional quality plays a role in democratization.

\footnotetext{
${ }^{17}$ Our likelihood ratio test value is 29.75 .
} 
We first confirm that standard logit estimation with country fixed effects included suggests a strong role for income. The coefficient estimates under logit however suffer from potential bias due to the incidental parameters problem. We therefore consider two corrections commonly used for this problem: The bias correction method of Fernandez-Val and the parameterization of fixed effects under Wooldridge estimation. Our results under these two methods differ: While both forms of estimation suggest a statistically significant relationship between income and democracy, the coefficient estimate under Fernandez-Val estimation is much larger than that under Wooldridge estimation.

Further analysis demonstrates that a substantial share of this discrepancy is attributable to sample differences between the two estimation methods, as Fernandez-Val estimation requires a balanced panel and is restricted to countries that exhibit at least one change in democratic status over the course of our sample period. Wooldridge estimation using the same reduced sample as that which is used in Fernandez-Val obtains a markedly higher coefficient estimate relative to that obtained under full-sample Wooldridge, but remains far below that obtained under Fernandez-Val, suggesting that sample differences do not account for all of the discrepancies between the results under the two estimation methods.

Even under the full sample Wooldridge estimation, however, there are income levels where the marginal impact of a change in income is predicted to have a notable impact on the probability of a country being a democracy. At the peak marginal value for the full-sample Wooldridge estimation a one standard deviation increase in income is estimated to be associated with a 19 percentage point increase in the probability of a country being a democracy. However, large standard errors for this estimate indicate that one cannot rule out very low impacts of income on democracy either.

It is important to reiterate that our analysis does not refute the possibility of a role for institutions in the determination of democratic status. First, even under our most favorable 
specifications and samples a substantial amount of variability in the data remains unexplained by income alone. Moreover, the sample reduction moving from Wooldridge to Fernandez-Val estimation is driven in large part by the need to omit countries with unchanging democratic status, as the timeinvariant fixed effect explains all of the variation from these countries. Countries that are democracies or autocracies throughout appear to have institutional characteristics markedly different from our Fernandez-Val balanced sample of changing countries. Countries that are democracies throughout appear to have superior institutional characteristics, while those that are autocracies appear to have inferior ones. Finally, our robustness exercise using the Acemoglu, et al (2009) data finds both a statistically significant positive role for both institutions, as proxied by constraints placed on chief executives, as well as income. We would therefore argue that the data support a role for both institutional and modernization-based development hypotheses. 


\section{References}

Acemoglu, Daron, Simon Johnson, James A. Robinson, and Pierre Yared, (2008), "Income and Democracy," American Economic Review, 98(3), 808-842.

Acemoglu, Daron, Simon Johnson, James A. Robinson, and Pierre Yared, (2009), "Reevaluating the Modernization Hypothesis," Journal of Monetary Economics, 56, 1043-1058.

Alvarez M, J.A.Cheibub, F.Limongi and A.Przeworski (1996), "Classifying Political Regimes", Studies in Comparative International Development, 31(2): 3-36

Benhabib, Jess, Alejandro Corvalan, and Mark M. Spiegel, (2013), "Income and Democracy: Evidence from Nonlinear Estimations," Economics Letters, 118, 489-492.

Boix, C. (2011). "Democracy, Development and the International System", American Political ScienceReview 105: 809-828.

Bobba, M., Coviello, D. (2007), "Weak instruments and weak identification in estimating the effects of education on democracy," Economics Letters, 96, 301-306.

Chamberlain G. (1980), "Analysis of covariance with qualitative data", Review of Economic Studies 47, pp. 225-238.

Cheibub, Jose A., Jennifer Gandhi, and James R. Vreeland, (2010), Democracy and Dictatorship Revisited," Public Choice, 143: 1-2, 67-101.

Coppedge, M., A. Alvarez, and C. Maldonado, (2008), "Two Persistent Dimensions of Democracy: Contestation and Inclusiveness," Journal of Politics, 70(3), 632-647.

Elkins, Z., (2000), "Gradations of Democracy? Empirical Tests of Alternative Conceptualizations", American Journal of Political Science, 44(2), 298-294.

Fernandez-Val, Ivan, (2009), "Fixed Effects Estimation of Structural Parameters and Marginal Effects in Panel Probit Models," Journal of Econometrics, 150(1), 71-85.

Gurr, Ted R., Keith Jaggers, and Will H. Moore, "The Transformation of the Western State: The Growth of Democracy: The Growth of Democracy, Autocracy, and State Power since 1800," Studies in Comparative International Development, 25, Spring, 51-72.

Heckman J.J. and T.E.MacCurdy (1980) "A Life Cycle Model of Female Labor Supply", Review of Economic Studies 47: 47-74.

Heckman, J.J., (1981) "The incidental parameters problem and the problem of initial conditions in estimating a discrete time-discrete data stochastic process", in: Manski, C.F., McFadden, D. (Eds.), Structural Analysis of Discrete Panel Data with Econometric Applications pp:179-195. 
Heston, Alan, Robert Summers and Bettina Aten, (2012), "Penn World Table Version 7.1," Center for International Comparisons of Production, Income and Prices at the University of Pennsylvania.

Honore Bo, (1993) "Orthogonality Conditions for Tobit Models with Fixed Effects and Lagged Dependent Variables", Journal of Econometrics, 59: 35-61.

Honore B. and E.Kyriazidou (2000) "Panel Data Discrete Choice Models with Lagged Dependent Variable", Econometrica 68(4): 839-874.

Lipset, Seymour M., (1959), "Some Social Requisites of Democracy: Economic Development and Political Legitimacy," American Political Science Review, 53(1), 69-105.

Maddison, Angus (2003), The World Economy: Historical Statistics, Paris: OECD

Moral-Benito, Enrique and Cristian Bartolucci, (2012), "Income and Democracy: Revisiting the Evidence," Economics Letters, 117, 844-847.

Munk, G., and J. Verkuilen, (2002), "Conceptualizing and Measuring Democracy: Evaluating Alternative Indices," Comparative Political Studies, 35(1): 5-34.

Murtin F., and R.Wacziarg, (2013), "The Democratic Transition", Journal of Economic Growth, forthcoming.

Neyman, J., and E. L. Scott, (1948), "Consistent estimates based on partially consistent observations," Econometrica, 16, 1-32.

Papaioannou, Elias and Gregorios Siourounis, (2008), "Economic and Social Factors Driving the Third Wave of Democratization," Journal of Comparative Economics, 36(3), 365-387.

Przeworski, Adam, Michael E. Alvarez, Jose Antonio Cheibub, and Fernando Limongi, (2000), Democracy and Development: Political Institutions and Well-Being in the World, 1950-1990," Cambridge University Press, New York.

Przeworski Adam and Fernando Limongi (1997), "Modernization: Theories and Facts", World Politics, 49:155-183.

Rabe-Hesketh, S., \& Skrondal, A. (2013). Avoiding biased versions of Wooldridge's simple solution to the initial conditions problem. Economics Letters120(2): 346-349.

Wooldridge Jeffrey M., (2005) "Simple Solutions to the Initial Conditions Problem in Dynamic, Non Linear Panel Data Models with Unobserved Heterogeneity", Journal of Applied Econometrics 20: 39-54. 


\begin{tabular}{|c|c|c|c|c|c|c|c|c|}
\hline & (1) & (2) & (3) & (4) & (5) & (6) & (7) & (8) \\
\hline & $\begin{array}{l}\text { Logit: } \\
\text { PWT } \\
7.1\end{array}$ & $\begin{array}{l}\text { Logit: } \\
\text { Maddison }\end{array}$ & $\begin{array}{l}\text { Logit } \\
\text { (country } \\
\text { FE): PWT } \\
7.1 \\
\end{array}$ & $\begin{array}{l}\text { Logit } \\
\text { (country } \\
\text { FE): } \\
\text { Maddison }\end{array}$ & $\begin{array}{l}\text { Fernande } \\
\text { z-Val: } \\
\text { PWT } 7.1\end{array}$ & $\begin{array}{l}\text { Fernande } \\
\text { z-Val: } \\
\text { Maddison }\end{array}$ & $\begin{array}{l}\text { Wooldridge } \\
\text { : PWT } 7.1\end{array}$ & $\begin{array}{l}\text { Wooldridg } \\
\text { e: } \\
\text { Maddison }\end{array}$ \\
\hline \multirow[t]{2}{*}{ L(democracy) } & $\begin{array}{l}0.74^{* *} \\
*\end{array}$ & $0.72 * * *$ & $0.10^{* *}$ & $0.21^{* * *}$ & $0.22 * * *$ & $0.28 * * *$ & $0.63^{* * *}$ & $0.64^{* * *}$ \\
\hline & $(0.03)$ & $(0.03)$ & $(0.05)$ & $(0.06)$ & $(0.06)$ & $(0.06)$ & $(0.04)$ & $(0.04)$ \\
\hline \multirow[t]{2}{*}{$\mathrm{L}$ (log income) } & $\begin{array}{l}0.04 * * \\
*\end{array}$ & $0.06 * * *$ & $0.34 * * *$ & $0.40 * * *$ & $0.32 * * *$ & $0.45 * * *$ & $0.08 * * *$ & $0.06 * *$ \\
\hline & $(0.01)$ & $(0.01)$ & $(0.08)$ & $(0.08)$ & $(0.12)$ & $(0.13)$ & $(0.03)$ & $(0.03)$ \\
\hline \multirow[t]{2}{*}{$\begin{array}{l}\text { Mean L(log } \\
\text { income) }\end{array}$} & & & & & & & $-0.05 *$ & -0.01 \\
\hline & & & & & & & $(0.03)$ & $(0.03)$ \\
\hline \multirow[t]{2}{*}{$\begin{array}{l}\text { Initial } \\
\text { democracy }\end{array}$} & & & & & & & $0.13 * * *$ & $0.08^{* * *}$ \\
\hline & & & & & & & $(0.04)$ & $(0.03)$ \\
\hline Observations & 1,114 & 1,093 & 431 & 466 & 216 & 306 & 1,114 & 1,093 \\
\hline Countries & 182 & 160 & 56 & 57 & 24 & 34 & 182 & 160 \\
\hline \multicolumn{9}{|c|}{$\begin{array}{l}\text { Note: Full sample panel logit estimation in columns } 1 \text { and } 2 \text {. Logit estimation in columns } 3 \text { and } 4 \text { with country fixed } \\
\text { effects, using sample restricted to countries with changing democracy statuses. Fernandez-Val estimation in } \\
\text { columns } 5 \text { and } 6 \text {, with a balanced panel of countries with changing democracy statuses. Full sample Wooldridge } \\
\text { estimation in columns } 7 \text { and } 8 \text {. Heteroskedasticity-consistent robust standard errors used throughout and reported } \\
\text { in parentheses. PWT } 7.1 \text { income data used in even columns, and Maddison income data in odd columns. Year fixed } \\
\text { effects included throughout. Dependent variable is Cheibub et al (2010) measure of democratic status, } D=1 \text { if } \\
\text { democratic, and } D=0 \text { if autocratic. } L(x) \text { represents one period lag of } x \text {. We report average marginal effects } \\
\text { throughout. } \\
* * * p<0.01, * * p<0.05, * p<0.1\end{array}$} \\
\hline
\end{tabular}




\begin{tabular}{|c|c|c|c|}
\hline \multicolumn{4}{|l|}{ Table 2a } \\
\hline Region & $\begin{array}{l}\text { Share of region in } \\
\text { overall sample }\end{array}$ & $\begin{array}{l}\text { Share of region's countries } \\
\text { that changed }\end{array}$ & $\begin{array}{l}\text { Share of region's obs } \\
\text { that changed }\end{array}$ \\
\hline Central Africa & $6.2 \%$ & $40 \%$ & $10.1 \%$ \\
\hline East and South Africa & $9.3 \%$ & $26.3 \%$ & $6.7 \%$ \\
\hline Western and North Africa & $15.5 \%$ & $37.5 \%$ & $9.8 \%$ \\
\hline India Subcontinent & $4.3 \%$ & $57.1 \%$ & $14.6 \%$ \\
\hline South Asia and Oceania & $10.5 \%$ & $19 \%$ & $5.1 \%$ \\
\hline Middle East & $7.5 \%$ & $0 \%$ & $1.2 \%$ \\
\hline China Subcontinent & $3 \%$ & $75 \%$ & $15.2 \%$ \\
\hline Latin America & $20.1 \%$ & $51.6 \%$ & $17.4 \%$ \\
\hline Eastern Europe & $5.5 \%$ & $36.8 \%$ & $14.8 \%$ \\
\hline North America (and Mexico) & $2.9 \%$ & $25 \%$ & $3.1 \%$ \\
\hline Western Europe & $14.5 \%$ & $15.8 \%$ & $2.5 \%$ \\
\hline Japan & $.8 \%$ & $0 \%$ & $0 \%$ \\
\hline Total & & $30.8 \%$ & $9.2 \%$ \\
\hline \multicolumn{4}{|c|}{$\begin{array}{l}\text { Note: The "overall sample" is the PWT } 7.1 \text { sample, in which democracy status, lagged democracy status, and } \\
\text { lagged log income from PWT } 7.1 \text { are non-missing. First column shows percentage of observations in the full sample } \\
\text { that are in the region. Second column shows the percentage of countries in the region that changed democracy } \\
\text { status at some point between } 1960 \text { and } 2000 \text {. Third column shows the proportion of observations in the region for } \\
\text { which the country's democracy status changed from the prior period to the current period. }\end{array}$} \\
\hline
\end{tabular}




\begin{tabular}{|c|c|c|c|c|c|}
\hline \multicolumn{6}{|l|}{ Table $\mathbf{2 b}$} \\
\hline & $\begin{array}{l}\text { Full } \\
\text { Sample }\end{array}$ & $\begin{array}{l}\text { Change in } \\
\text { Status }\end{array}$ & $\begin{array}{l}\text { No } \\
\text { Change }\end{array}$ & $\begin{array}{l}\text { No Change } \\
(D=0)\end{array}$ & $\begin{array}{l}\text { No Change } \\
(D=1)\end{array}$ \\
\hline \# of Obs & 1114 & 431 & 683 & 375 & 308 \\
\hline \# of countries & 182 & 56 & 126 & 71 & 55 \\
\hline \% Democracy & $44.70 \%$ & $44.08 \%$ & $45.10 \%$ & $0.00 \%$ & $100.00 \%$ \\
\hline Log Income & 8.26 & 7.91 & 8.48 & 7.69 & 9.45 \\
\hline Log Population & 9.09 & 9.19 & 9.02 & 8.76 & 9.40 \\
\hline Latitude & 0.27 & 0.22 & 0.31 & 0.22 & 0.42 \\
\hline Log Pop Density in 1500 & 0.42 & 0.46 & 0.39 & 0.77 & -0.38 \\
\hline Settler Mortality & 4.69 & 4.93 & 4.43 & 4.92 & 3.74 \\
\hline Year of Independence & 1911 & 1899 & 1918 & 1942 & 1888 \\
\hline Freedom Index (EFW) & 5.80 & 5.36 & 6.14 & 5.39 & 6.67 \\
\hline Standard deviation of log income & 1.26 & 0.98 & 1.36 & 1.16 & 0.86 \\
\hline \multicolumn{6}{|c|}{$\begin{array}{l}\text { Note: "Full sample" refers to the PWT } 7.1 \text { sample, in which all observations are from } 1960-2000 \text { and have non- } \\
\text { missing democracy status, lagged democracy status, and lagged log PWT } 7.1 \text { income. The other four samples } \\
\text { shown in this table are subsets of the full sample. "Change in Status" refers the countries that changed democracy } \\
\text { status at some point in } 1960-2000 \text {, while "No Change" refers to countries that did not change democracy status. } \\
\text { "No Change }(D=0) \text { " are countries that remained autocracies throughout } 1960-2000 \text {, and "No Change }(D=1) \text { " are } \\
\text { countries that remained democracies throughout } 1960-2000 \text {. }\end{array}$} \\
\hline
\end{tabular}




\begin{tabular}{|c|c|c|c|c|}
\hline & (1) & (2) & (3) & (4) \\
\hline & $\begin{array}{l}\text { Wooldridge: } \\
\text { PWT } 7.1\end{array}$ & $\begin{array}{l}\text { Wooldridge: } \\
\text { Maddison }\end{array}$ & $\begin{array}{l}\text { Diff Income (chg vs } \\
\text { nochg): PWT } 7.1\end{array}$ & $\begin{array}{l}\text { Diff Income (chg vs nochg): } \\
\text { Maddison }\end{array}$ \\
\hline \multirow[t]{2}{*}{ L(democracy) } & $0.33^{* * *}$ & $0.41 * * *$ & $0.62 * * *$ & $0.62 * * *$ \\
\hline & $(0.05)$ & $(0.05)$ & $(0.05)$ & $(0.05)$ \\
\hline \multirow[t]{2}{*}{$\mathrm{L}($ log income $)$} & $0.15^{* *}$ & $0.17^{* *}$ & & \\
\hline & $(0.07)$ & $(0.08)$ & & \\
\hline \multirow[t]{2}{*}{ Mean L(log income) } & -0.07 & -0.08 & & \\
\hline & $(0.07)$ & $(0.09)$ & & \\
\hline \multirow[t]{2}{*}{ Initial democracy } & 0.02 & -0.02 & $0.11 * * *$ & $0.07 * *$ \\
\hline & $(0.04)$ & $(0.04)$ & $(0.03)$ & $(0.03)$ \\
\hline \multirow[t]{2}{*}{$\mathrm{L}($ log income) * changing_country } & & & $0.16^{* * *}$ & $0.15^{* * *}$ \\
\hline & & & $(0.05)$ & $(0.05)$ \\
\hline \multirow[t]{2}{*}{$L(\log$ income $) *$ fixed_country } & & & $-0.06^{* *}$ & -0.03 \\
\hline & & & $(0.03)$ & $(0.03)$ \\
\hline \multirow[t]{2}{*}{$\begin{array}{lll}\begin{array}{l}\text { Mean L(log } \\
\text { changing_country }\end{array} & \text { income }) & * \\
\end{array}$} & & & $-0.12^{* *}$ & -0.08 \\
\hline & & & $(0.05)$ & $(0.05)$ \\
\hline \multirow[t]{2}{*}{ 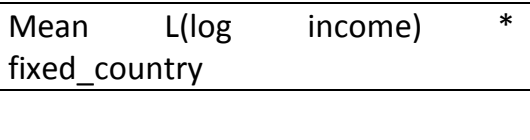 } & & & $0.09 * * *$ & $0.09 * * *$ \\
\hline & & & $(0.03)$ & $(0.03)$ \\
\hline Observations & 431 & 466 & 1,114 & 1,093 \\
\hline Countries & 56 & 57 & 182 & 160 \\
\hline \multicolumn{5}{|c|}{$\begin{array}{l}\text { Note: Wooldridge estimation in columns } 1 \text { and } 2 \text {, using sample restricted to countries with changing democracy statuses. } \\
\text { Columns } 3 \text { and } 4 \text { show the same logistic regression, except we allow the effect of lagged income to differ between countries } \\
\text { that change democracy status and countries that do not. Heteroskedasticity-consistent robust standard errors used } \\
\text { throughout and reported in parentheses. PWT } 7.1 \text { income data used in even columns, and Maddison income data in odd } \\
\text { columns. Year fixed effects included throughout. Dependent variable is Cheibub et al (2010) measure of democratic status, } \\
D=1 \text { if democratic, and } D=0 \text { if autocratic. } L(x) \text { represents one period lag of } x \text {. We report average marginal effects throughout. } \\
* * * p<0.01, * * p<0.05, * p<0.1\end{array}$} \\
\hline
\end{tabular}




\begin{tabular}{|c|c|c|c|c|c|c|c|c|}
\hline & (1) & (2) & (3) & (4) & (5) & (6) & (7) & (8) \\
\hline & $\begin{array}{l}\text { Ex. } \\
\text { Eastern } \\
\text { Europe: } \\
\text { PWT 7.1 }\end{array}$ & $\begin{array}{l}\text { Ex. } \\
\text { Eastern } \\
\text { Europe: } \\
\text { Maddison }\end{array}$ & $\begin{array}{l}\text { Ex. } \\
\text { Western } \\
\text { Europe: } \\
\text { PWT } 7.1\end{array}$ & $\begin{array}{l}\text { Ex. } \\
\text { Western } \\
\text { Europe: } \\
\text { Maddison }\end{array}$ & $\begin{array}{l}\text { Ex. Latin } \\
\text { America: } \\
\text { PWT } 7.1\end{array}$ & $\begin{array}{l}\text { Ex. Latin } \\
\text { America: } \\
\text { Maddison }\end{array}$ & $\begin{array}{l}\text { Ex. } \\
\text { Middle } \\
\text { East: } \\
\text { PWT } 7.1\end{array}$ & $\begin{array}{l}\text { Ex. } \\
\text { Middle } \\
\text { East: } \\
\text { Maddison }\end{array}$ \\
\hline \multirow[t]{2}{*}{ L(democracy) } & $0.33^{* * *}$ & $0.39 * * *$ & $0.33^{* * *}$ & $0.41 * * *$ & $0.33^{* * *}$ & $0.44 * * *$ & $0.33^{* * *}$ & $0.39 * * *$ \\
\hline & $(0.06)$ & $(0.05)$ & $(0.06)$ & $(0.05)$ & $(0.07)$ & $(0.06)$ & $(0.05)$ & $(0.05)$ \\
\hline \multirow[t]{2}{*}{$\mathrm{L}$ (log income) } & $0.14^{*}$ & $0.18^{* *}$ & 0.12 & $0.15^{*}$ & 0.12 & $0.15^{*}$ & $0.15^{* *}$ & $0.15^{*}$ \\
\hline & (0.08) & $(0.08)$ & $(0.07)$ & (0.08) & (0.08) & $(0.08)$ & (0.07) & (0.08) \\
\hline \multirow[t]{2}{*}{$\begin{array}{ll}\text { Mean } & \text { L(log } \\
\text { income) }\end{array}$} & -0.06 & -0.08 & -0.04 & -0.07 & -0.05 & -0.08 & -0.07 & -0.05 \\
\hline & (0.08) & (0.09) & $(0.08)$ & (0.09) & $(0.08)$ & (0.09) & $(0.07)$ & (0.09) \\
\hline \multirow[t]{2}{*}{ Initial democracy } & 0.03 & -0.03 & 0.01 & -0.03 & 0.03 & -0.04 & 0.02 & -0.01 \\
\hline & (0.05) & $(0.04)$ & (0.04) & $(0.04)$ & $(0.06)$ & $(0.04)$ & $(0.04)$ & $(0.04)$ \\
\hline Observations & 382 & 405 & 404 & 439 & 295 & 340 & 431 & 457 \\
\hline Countries & 49 & 50 & 53 & 54 & 40 & 43 & 56 & 56 \\
\hline \multicolumn{9}{|c|}{$\begin{array}{l}\text { Wooldridge estimation used in all columns. The sample used in each column consists of countries with changing } \\
\text { democracy statuses, excluding countries from one region of the world. Columns } 1 \text { and } 2 \text { exclude countries in } \\
\text { Eastern Europe. Columns } 3 \text { and } 4 \text { exclude countries from Western Europe. Columns } 5 \text { and } 6 \text { exclude countries in } \\
\text { Latin America. Columns } 7 \text { and } 8 \text { exclude countries from the Middle East. Heteroskedasticity-consistent robust } \\
\text { standard errors used throughout and reported in parentheses. PWT } 7.1 \text { income data used in even columns, and } \\
\text { Maddison income data in odd columns. Year fixed effects included throughout. Dependent variable is Cheibub et al } \\
\text { (2010) measure of democratic status, } D=1 \text { if democratic, and } D=0 \text { if autocratic. } L(x) \text { represents one period lag of } x \text {. } \\
\text { We report average marginal effects throughout. } \\
* * * p<0.01, * * p<0.05, * p<0.1\end{array}$} \\
\hline
\end{tabular}




\begin{tabular}{|c|c|c|c|c|c|}
\hline & (1) & (2) & (3) & (4) & (5) \\
\hline & $\begin{array}{l}\text { Logit } \\
\text { (country FE; } \\
\text { unbalanced) }\end{array}$ & $\begin{array}{l}\text { Logit } \\
\text { (country FE; } \\
\text { balanced) }\end{array}$ & $\begin{array}{l}\text { Fernandez- } \\
\text { Val(country } \\
\text { FE; balanced) }\end{array}$ & $\begin{array}{l}\text { Logit } \\
\text { (Wooldridge; } \\
\text { country FE; } \\
\text { unbalanced) }\end{array}$ & $\begin{array}{l}\text { Logit(Wooldridge; } \\
\text { country FE; unbalanced) }\end{array}$ \\
\hline \multirow[t]{2}{*}{ L(democracy) } & $0.41 * * *$ & $0.49 * * *$ & $0.39 * * *$ & $0.68 * * *$ & $0.56 * * *$ \\
\hline & $(0.04)$ & $(0.06)$ & $(0.09)$ & $(0.03)$ & $(0.03)$ \\
\hline \multirow[t]{2}{*}{$\mathrm{L}$ (log income) } & $0.18 * * *$ & $0.23^{* *}$ & $0.22 *$ & $0.09 * * *$ & $0.13^{* * *}$ \\
\hline & $(0.05)$ & $(0.11)$ & $(0.12)$ & $(0.02)$ & $(0.04)$ \\
\hline \multirow[t]{2}{*}{$\begin{array}{ll}\text { Mean } & \text { L(log } \\
\text { income) } & \\
\end{array}$} & & & & -0.03 & -0.04 \\
\hline & & & & $(0.02)$ & $(0.05)$ \\
\hline \multirow[t]{2}{*}{$\begin{array}{l}\text { Initial } \\
\text { democracy }\end{array}$} & & & & $0.04 * *$ & -0.03 \\
\hline & & & & $(0.02)$ & $(0.03)$ \\
\hline Observations & 866 & 238 & 238 & 1,482 & 866 \\
\hline Countries & 74 & 14 & 14 & 156 & 74 \\
\hline \multicolumn{6}{|c|}{$\begin{array}{l}\text { Column } 1 \text { shows logit estimates without country fixed effects in the } 1905-2000 \text { sample, restricted to } \\
\text { countries that changed democracy status in that time period. Column } 2 \text { shows the same specification as } \\
\text { Column } 1 \text { estimated on a balanced panel. Column } 3 \text { shows Fernandez-Val estimates using the same sample } \\
\text { as in Column } 2 \text {. Column } 4 \text { reports Wooldridge estimates for the full } 1905-2000 \text { sample. Column } 5 \text { reports } \\
\text { Wooldridge estimates for the full } 1905-2000 \text { sample restricted to countries that changed democracy status in } \\
\text { that time period. Heteroskedasticity-consistent robust standard errors used throughout and reported in } \\
\text { parentheses. Maddison income data and year fixed effects used throughout. Dependent variable is Cheibub } \\
\text { et al (2010) measure of democratic status, } D=1 \text { if democratic, and } D=0 \text { if autocratic. } L(x) \text { represents one } \\
\text { period lag of } x \text {. We report average marginal effects throughout. } \\
* * * p<0.01, * * p<0.05, * p<0.1\end{array}$} \\
\hline
\end{tabular}




\begin{tabular}{|c|c|c|c|c|c|c|c|c|}
\hline & (1) & (2) & (3) & (4) & (5) & (6) & (7) & (8) \\
\hline & $\begin{array}{l}\text { OLS full } \\
\text { sample }\end{array}$ & $\begin{array}{l}\text { OLS full } \\
\text { sample }\end{array}$ & $\begin{array}{l}\text { Logit full } \\
\text { sample }\end{array}$ & $\begin{array}{l}\text { Logit full } \\
\text { sample }\end{array}$ & $\begin{array}{l}\text { OLS } \\
\text { changing } \\
\text { sample }\end{array}$ & $\begin{array}{l}\text { OLS } \\
\text { changing } \\
\text { sample }\end{array}$ & $\begin{array}{l}\text { Logit } \\
\text { changing } \\
\text { sample }\end{array}$ & $\begin{array}{l}\text { Logit } \\
\text { changing } \\
\text { sample }\end{array}$ \\
\hline \multirow[t]{2}{*}{ L(democracy) } & $0.61 * * *$ & $0.61 * * *$ & $0.52 * * *$ & $0.52^{* * *}$ & $0.33^{* * *}$ & $0.33^{* * *}$ & $0.32 * * *$ & $0.32^{* * *}$ \\
\hline & $(0.06)$ & $(0.06)$ & $(0.07)$ & $(0.07)$ & $(0.06)$ & $(0.06)$ & $(0.06)$ & $(0.06)$ \\
\hline \multirow[t]{2}{*}{ L(log Income) } & $0.04 *$ & $0.04 *$ & 0.03 & 0.03 & $0.15^{* * *}$ & $0.15^{* * *}$ & $0.14^{* * *}$ & $0.15^{* * *}$ \\
\hline & $(0.02)$ & $(0.02)$ & $(0.02)$ & $(0.02)$ & $(0.04)$ & $(0.05)$ & $(0.04)$ & $(0.05)$ \\
\hline \multirow{2}{*}{$\begin{array}{l}\text { Constraint on } \\
\text { executive at } \\
\text { independence }\end{array}$} & $0.13^{* *}$ & $0.13^{* *}$ & $0.14^{* * *}$ & $0.14^{* * *}$ & $0.21 * * *$ & $0.20 * * *$ & $0.22^{* * *}$ & $0.21^{* * *}$ \\
\hline & $(0.05)$ & $(0.05)$ & $(0.05)$ & $(0.05)$ & $(0.05)$ & $(0.06)$ & $(0.06)$ & $(0.07)$ \\
\hline \multirow{2}{*}{$\begin{array}{l}\text { Year of } \\
\text { independence }\end{array}$} & $-0.13^{* * *}$ & $-0.13 * * *$ & $-0.11 * * *$ & $-0.11 * * *$ & -0.06 & -0.06 & -0.07 & -0.07 \\
\hline & (0.03) & (0.04) & (0.03) & (0.03) & (0.04) & $(0.04)$ & (0.05) & (0.05) \\
\hline \multirow{2}{*}{$\begin{array}{l}\text { Population } \\
\text { density in } 1500\end{array}$} & & 0 & & 0 & & 0.01 & & 0 \\
\hline & & $(0.01)$ & & $(0.01)$ & & $(0.02)$ & & $(0.02)$ \\
\hline Observations & 563 & 563 & 563 & 563 & 219 & 219 & 219 & 219 \\
\hline R-squared & 0.60 & 0.60 & & & 0.38 & 0.38 & & \\
\hline countries & 79 & 79 & 79 & 79 & 29 & 29 & 29 & 29 \\
\hline \multicolumn{9}{|c|}{$\begin{array}{l}\text { Note: Columns } 1 \text { and } 2 \text { show OLS estimates reported in AJRY (2009) using their sample of former European } \\
\text { colonies in } 1960-2000 \text { and using the Pzeworski et al (2000) measure of democratic status as the dependent } \\
\text { variable. Columns } 3 \text { and } 4 \text { show logit estimates that correspond with columns } 1 \text { and } 2 \text {. Columns } 5,6,7,8 \text { show } \\
\text { estimates when we restrict the sample to countries with changing democracy statuses. All specifications include } \\
\text { year fixed effects. Standard errors clustered by country are shown in parentheses. For logit specifications, we } \\
\text { report average marginal effects. } \\
* * * p<0.01, * * p<0.05, * p<0.1\end{array}$} \\
\hline
\end{tabular}




\section{Appendix Table A1}

Standard Deviations of Log Income in Study Samples

\begin{tabular}{llll} 
Sample & Balanced? & \# observations & Std Deviation of income \\
\hline PWT Full & No & 1,114 & 1.26 \\
Mad Full & No & 1,093 & 1.07 \\
PWT Changing & No & 431 & 0.98 \\
Mad Full & No & 466 & 0.85 \\
PWT Changing & Yes & 216 & 0.69 \\
Mad Changing & Yes & 306 & 0.71 \\
1900 Penn Full & No & 1,482 & 0.97 \\
1900 Penn Changing & Yes & 866 & 0.85
\end{tabular}

Note: Standard deivations of income in various estimation samples. Penn refers to the Penn World Tables 7.1 data set, while Mad refers to the Madison income data. 1900 Penn refers to extended time series sample. 
Figure 1: Marginal effects for different estimations
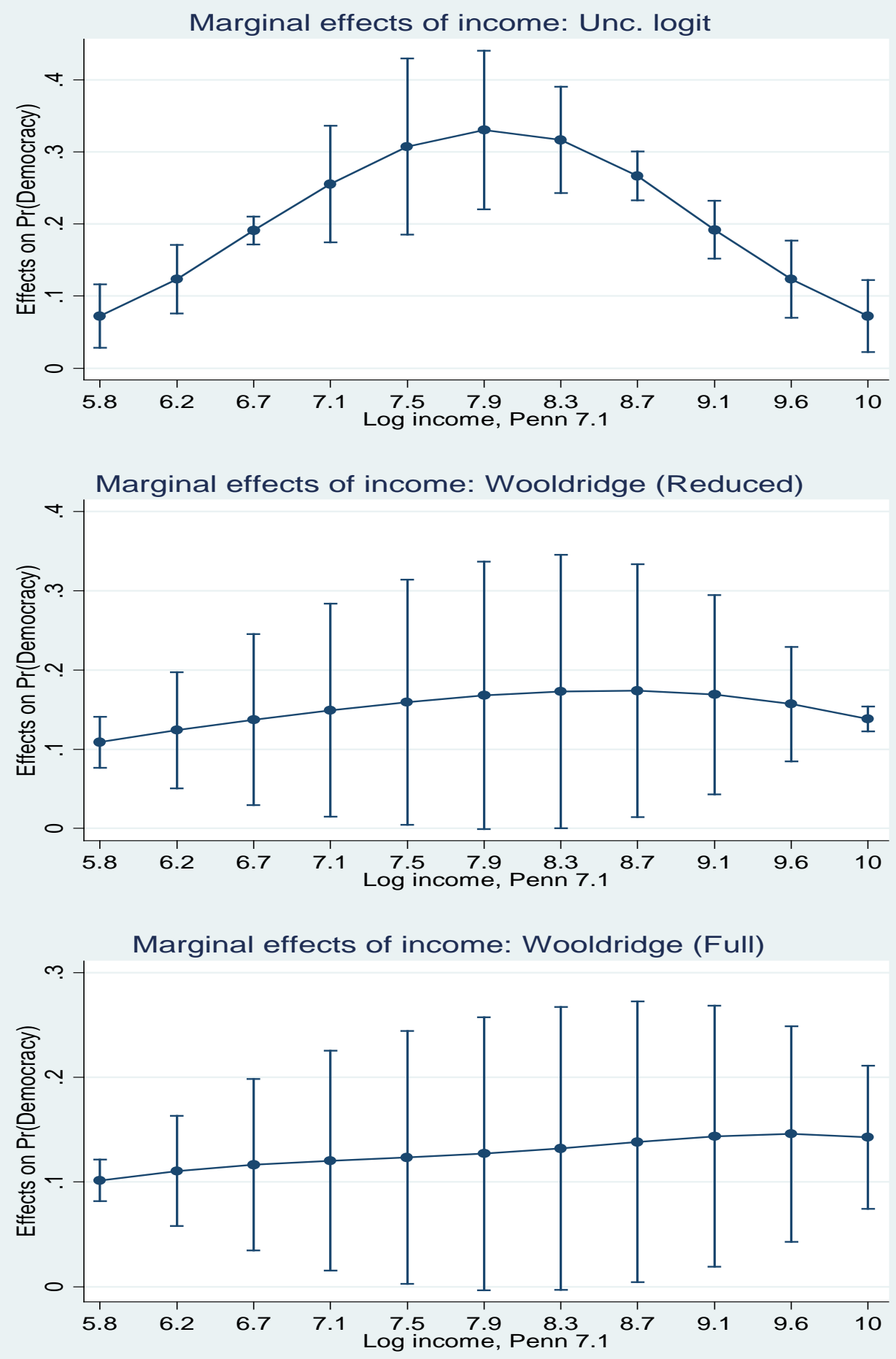
Figure 2: Probit on income in 1970

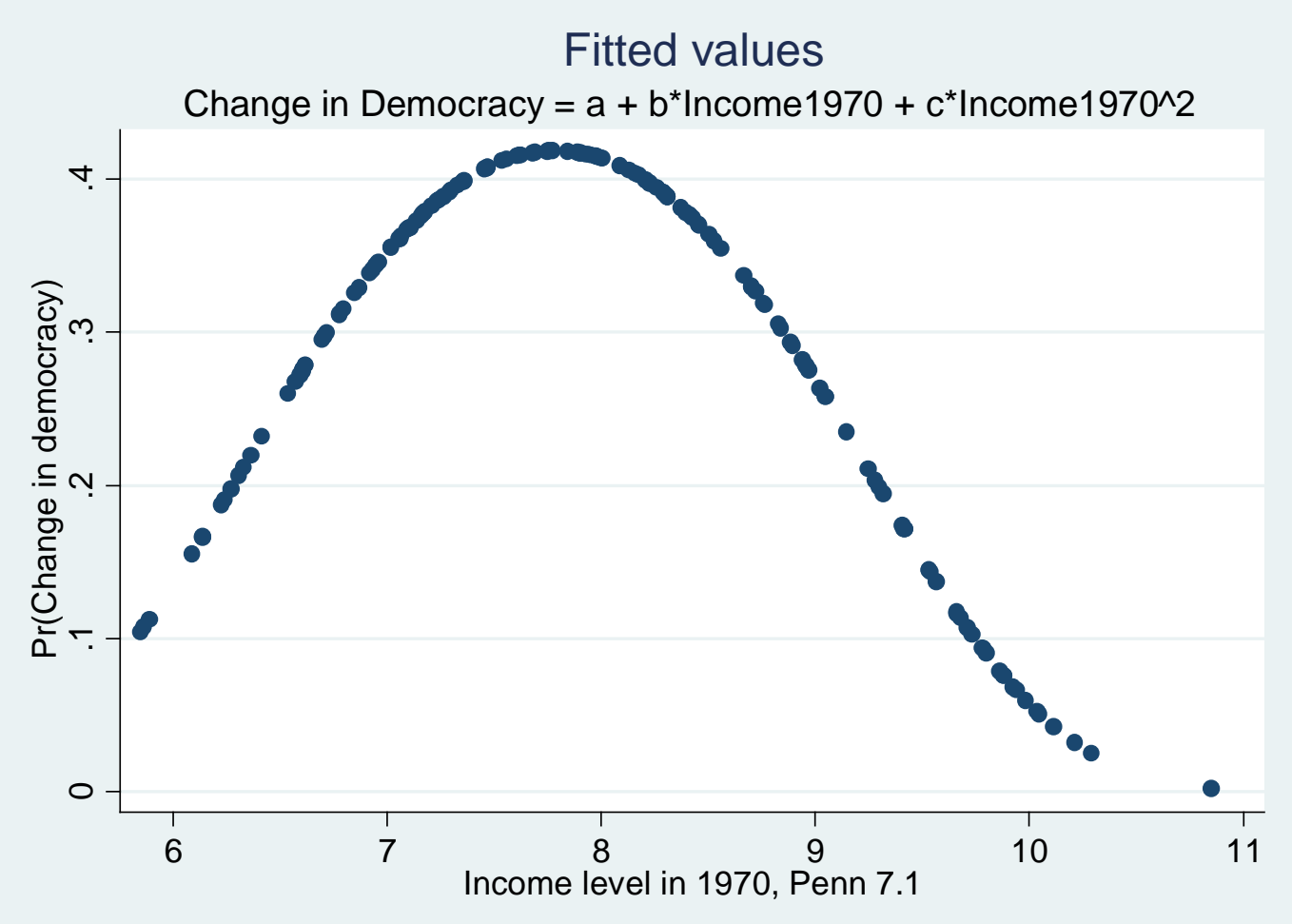

